\title{
LA DUALIDAD DEL MERCADO DE TRABAJO COMO UNA DE LAS CAUSAS DE LA CRISIS ACTUAL, AUNQUE NO LA ÚNICA
}

\section{Duality of labour market as one of the causes of the current crisis, but not the only one}

JoRdi GaRcía Viña. Doctor en Derecho. Catedrático de Derecho del Trabajo y de la Seguridad Social. Universidad de Barcelona. España

CONVIDADO

RECEBIDO EM:12/02/2016

APROVADO EM:2/02/2016

DOI: $10.5585 /$ RDB.V11 I5.345

\section{Resumen}

Una de las máximas preocupaciones de cualquiera de los gobiernos de los países de la Unión Europea es la lucha contra el desempleo y la creación de empleo. La principal herramienta para solucionar este grave problema consiste en el crecimiento económico, especialmente en el sector privado, ya que, la mejora de la situación económica es el primer motor de la creación de empleo. Sin embargo, también otros factores pueden colaborar en este proceso, especialmente los que se refieren a aspectos públicos, tales como la necesidad de continuar con las reformas en la legislación laboral y la mejora de los servicios públicos de empleo.

Palabras Clave: DUAlidad, empleo y contrato

\begin{abstract}
One of the main concerns of any of the governments of the European Union countries is to combat unemployment and job creation. The main tool to solve this serious problem is economic growth, especially in the private sector, since the improvement of the economic situation is the first engine of job creation. However, other factors may contribute to this process, especially those related to public services such as the need to continue reforms in labor laws and improving public services employment aspects.
\end{abstract}




\section{1. ¿DE DÓNDE VENIMOS?}

Cuando se trata de comprender la situación actual del mercado de trabajo en la Unión Europea y, por extensión, la realidad en España, nada se entiende si no se atiende a la crisis económica generalizada que sufre principalmente Europa desde el desplome del precio del petróleo.

Sin perjuicio de las consecuencias que tuvieron las dos guerras mundiales, en Europa, entre los años 1945 a 1973 se establece un sistema de empleo llamado "fordismo", cuya relación laboral presentaba las siguientes notas principales.

$\checkmark \quad$ La contratación era de duración indeterminada, o dicho de otra manera, la mayoría de todos los contratos son indefinidos.

$\checkmark \quad$ Todos estos contratos indefinidos eran celebrados a tiempo completo, de manera que el tiempo parcial quedaba relegada a supuestos muy concretos.

$\checkmark \quad$ Esta prestación se realizaba, casi durante toda la vida del trabajador, por cuenta de un único empleador.

$\checkmark \quad$ Existía una importante protección contra el despido injustificado.

$\checkmark \quad$ Se produjo un importante desarrollo del Estado del Bienestar, entendido como la máxima preocupación por parte de los Estados hacia la protección social de los trabajadores y usuarios del sistema público de seguridad social.

El conflicto árabe-israelí de 1973 originó una situación económica recesiva, que si bien en apariencia no era nada más que una coyuntura adversa, pronto se reveló como un estado de crisis con evidentes rasgos de permanencia, al asociarse a ella la incorporación al sistema productivo de importantes cambios tecnológicos. Por tanto, esta "crisis del petróleo" supuso una crisis estructural, de la que se pueden destacar los siguientes factores económicos: competencia internacional, innovación técnica, modificaciones radicales en la organización de la producción, nuevos métodos de gestión de la mano de obra, evolución de las aspiraciones y necesidades de los trabajadores, entre muchas otras.

Esta metamorfosis significó un debate sobre la flexibilidad en el empleo, que puso en tela de juicio este modelo de relaciones laborales clásico. Las notas principales de la crisis de este modelo fueron las siguientes: 
$\checkmark \quad$ Multiplicación de los contratos laborales de duración determinada.

$\checkmark \quad$ Normalización del trabajo a tiempo parcial.

$\checkmark \quad$ Externalización de la producción y del empleo.

$\checkmark \quad$ Aparición de economía clandestina o sumergida.

Si se lleva a cabo un breve análisis de cada nota, se puede observar que apareció una multiplicación de las modalidades de contratación por tiempo determinado; especialmente en aquellos países donde el despido era causal y de coste muy elevado. Respecto al trabajo a tiempo parcial, ha tenido un gran desarrollo porque favorece la flexibilidad de las empresas. Aparecieron las subcontrataciones con otras empresas para todas aquellas actividades de servicio, y la figura de las empresas de empleo temporal. Por último, apareció la economía sumergida como medio de reducir los costes laborales. En esta situación se produjo una oposición crítica a la situación anterior por entender que engendraba rigideces incompatibles con las necesidades de las empresas, que necesitaban adaptarse a un entorno económico cambiante y competitivo. Todo ello, replanteando el papel del sector público, desde un doble punto de vista: regulador del mercado y actor principal del gasto.

Esta situación económica aconsejaba cualquier tipo de reforma: la internacionalización de la economía, el Acuerdo General sobre Aranceles y Comercio y el Tratado de Libre Comercio, la ascensión en el ranking de competitividad de los países del sureste asiático, los profundos cambios estructurales en cuanto a la organización de las empresas, concretamente el just in time. Esta situación tuvo más repercusiones en España: la baja productividad, los altos costes laborales que fueron considerados como la principal causa del desempleo, así como los altos niveles de paro.

La clave para la solución de la crisis fue la búsqueda de la flexibilidad en las relaciones laborales. Este concepto, de naturaleza extremadamente amplia, presenta lecturas positivas y negativas, que pueden observarse claramente desde tres puntos de vista:

$\checkmark \quad$ Desregulación del mercado de trabajo. Pretende la búsqueda de una mejora de los niveles de empleo, justificando el objetivo del crecimiento del empleo sobre la estabilidad en el mismo y la defensa de la competitividad empresarial a costa de una cierta pérdida de beneficios sociales por parte de los trabajadores.

$\checkmark \quad$ Desregulación de las condiciones de trabajo en favor de la negociación colectiva. Se potencia por medio de la flexibilización de los requisitos de negociación y la admisión de los pactos colectivos. Además, se limita la intervención de la Administración pública en la regulación de las condiciones de trabajo. 
$\checkmark \quad$ Reducción del gasto del sistema de la Seguridad Social, por ejemplo, respecto a las prestaciones de desempleo, incapacidad temporal, jubilación, o en la exclusión o reducción de la cobertura de ciertos colectivos.

Esta situación de replanteamiento de los principios clásicos vuelve a estar presente en la actualidad. De hecho, la crisis financiera iniciada en el verano de 2007 en Estados Unidos y la posterior recesión económica a escala mundial supusieron el inicio de una crisis económica y de empleo de enormes proporciones que difícilmente permite anunciar su salida.

En la Unión Europea el número de personas desempleadas ha aumentado de manera vertiginosa por este motivo. Aunque este incremento afecta a todos los Estados miembros y a todos los colectivos, ya sean hombres o mujeres y/o jóvenes o personas mayores, el impacto ha sido muy diverso y en esta situación pueden influir diversos factores, como las estructuras productivas e institucionales de cada país, así como las medidas económicas y de empleo puestas en práctica.

Conforme a las estadísticas de Eurostat, el número de personas desempleadas se ha incrementado mensualmente desde el mes de marzo de 2008 donde se observan los porcentajes más bajos. España e Italia fueron los primeros países donde el desempleo empezó a incrementarse, aproximadamente a partir de mayo de 2007, seguidos de Irlanda, Luxemburgo, Letonia y Lituania, en la segunda mitad del mismo año y Francia a principios del año siguiente.

Desde el mes de mayo de 2007, el número de personas desempleadas en los países que tienen implantado el euro se ha incrementado en 3.7 millones hasta alcanzar los 15 millones, mientras que en el mismo período, si se tiene en cuenta todos los países que forman la Unión Europea, el desempleo ha subido en 5.4 millones hasta superar los 21.5 millones $^{1}$.

http:/ / epp.eurostat.ec.europa.eu/statistics_explained/index.php/Unemployment_statistics 


\section{Gráfico número 1. Desempleo}

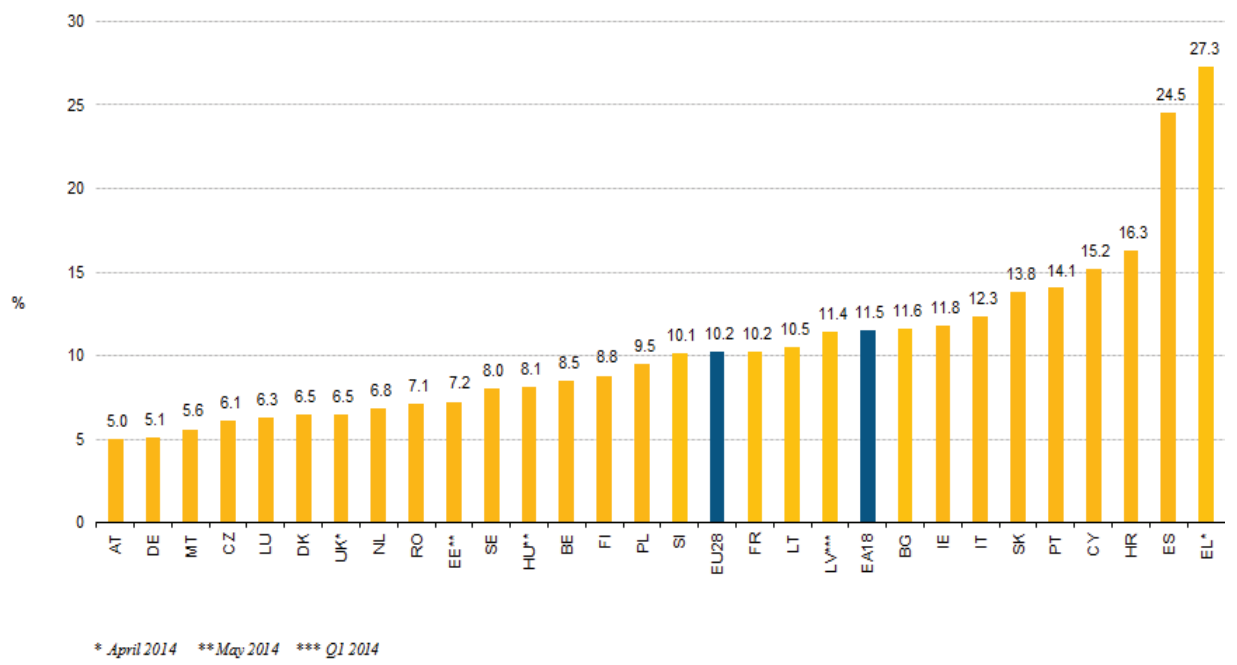

Fuente: Eurostat.

No sólo hay que tener en cuenta el momento del arranque de la situación de desempleo, sino también la intensidad, que también es muy diferente si se comparan los distintos países. En la mayoría de países, el incremento medio mensual ha sido del 0,1 a $0,2 \%$; sin embargo, estos incrementos han sido mucho mayores en los países bálticos y en España ${ }^{2}$.

Por otra parte, el desempleo no ha afectado por igual a todos los trabajadores: el peso de la crisis ha recaído principalmente en los trabajadores jóvenes; el desempleo masculino ha evolucionado de forma más negativa que el femenino $\mathrm{y}$, por último, los ajustes del empleo ante la crisis han sido mucho mayores entre los trabajadores con contratos temporales y/o niveles formativos más bajos ${ }^{3}$.

Eurostat.Sharp incrase in unemployment in the EU.Statistics in focus.53/2009.

Eurostat.The impact of the crisis on employment.Statitics in focus.79/2009. 


\section{Gráfico número 2. Desempleo juvenil}

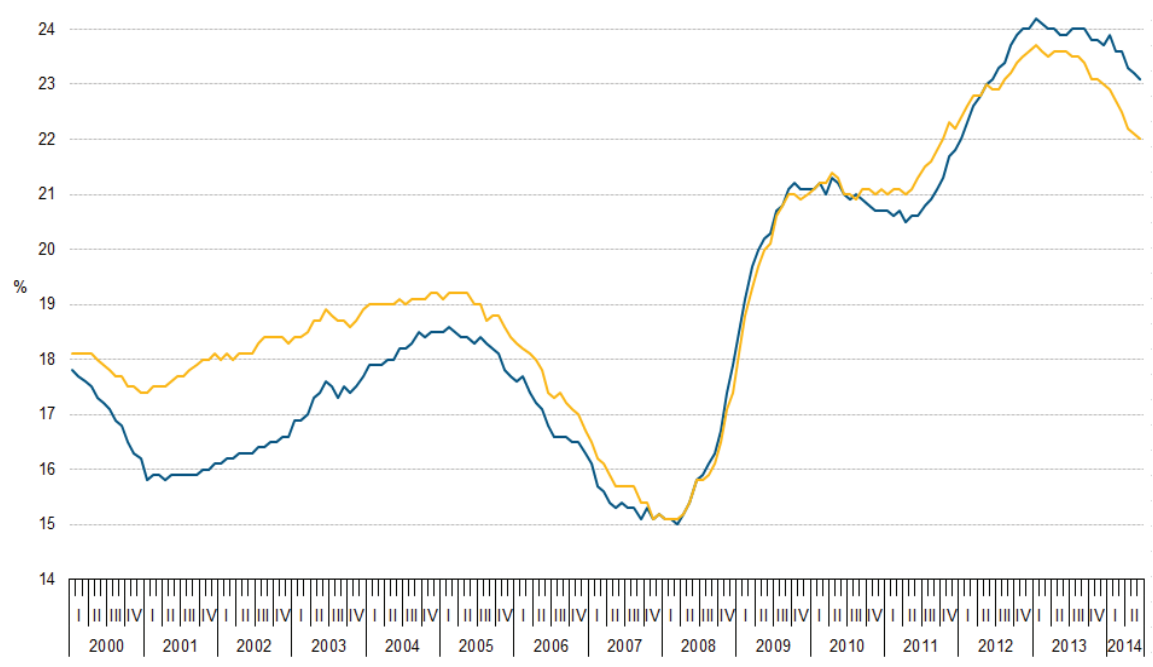

Fuente: Eurostat.

En este contexto, aparecen dos incógnitas de difícil resolución: hasta cuándo va a durar la crisis económica y qué incidencia va a tener la recuperación de la crisis con el desempleo.

La Organización para la Cooperación y el Desarrollo Económico estima que el impacto de la crisis en el empleo se va a prolongar más allá del inicio de la recuperación económica. El aumento del paro de larga duración, la pérdida de capital humano a través de la descualificación de los parados de larga duración, hará más difícil la recuperación de los niveles de empleo anteriores a la situación de la crisis, por lo que éstos pueden tardar mucho tiempo en reponerse o pueden incluso no volver a alcanzarse ${ }^{4}$.

De la misma manera, la Comisión Europea espera un empeoramiento de las condiciones del mercado de trabajo durante todavía algún tiempo después de que comience a producirse la reactivación del crecimiento económico, por lo que estima que la Unión Europea puede alcanzar durante 2014 los 27 millones de residentes de la Unión Europea de paro5.

OECD (2014), OECD Employment Outlook 2014, OECD Publishing. DOI: $10.1787 /$ empl_outlook-2014-en.

http:/ / europa.eu/pol/pdf/flipbook/es/employment_es.pdf. 
Ante la crisis económica y laboral, la gran mayoría de los países industrializados han puesto en práctica amplios conjuntos de políticas activas y de protección, de carácter coyuntural, para contrarrestar los efectos sociales y en el empleo de la recesión económica. La tendencia general es, a diferencia de crisis anteriores, incrementar de manera significativa el esfuerzo en políticas activas de mercado de trabajo a medida que se han ido extendiendo los efectos de la crisis en forma de aumento del desempleo, sobre todo en aquellos países que habían adoptado medidas anticrisis de forma temprana, aunque también se pone de manifiesto que el nivel global de gasto sigue siendo pequeño en proporción al aumento del paro ${ }^{6}$.

En un informe, la Organización Internacional del Trabajo ya había detectado 32 medidas adoptadas en el ámbito nacional Las más frecuentemente adoptadas han consistido en nueva inversión pública en infraestructuras (el $87 \%$ ), apoyo a las pequeñas y medianas empresas en forma de ayudas y rebajas fiscales $(78 \%)$, la mejora del acceso de éstas empresas al crédito (74\%), el incremento de las políticas de formación profesional (63\%), el aumento de las transferencias en efectivo a las familias (54\%), la creación o la ampliación de programas de empleo específicos (52 $\%$ ), el refuerzo de los servicios públicos de empleo (46\%), modificaciones en las pensiones de jubilación (44\%), o un mayor acceso a las prestaciones de salud (37 $\%)$.

Concluye el informe que, si bien todos los países han dado mucha prioridad a las nuevas inversiones en infraestructuras como forma de promover la actividad económica y el empleo, los países de nivel económico medio y bajo han realizado un significativo esfuerzo, además, en ampliar la protección social, mientras que los países de ingresos altos han optado más por invertir en las políticas de mercado de trabajo ${ }^{7}$.

En la Unión Europea, la Estrategia de Lisboa para el crecimiento y el empleo se puso en marcha en 2000 como respuesta a los desafíos de la globalización y del envejecimiento. El Consejo Europeo fijó como objetivo de la Estrategia que en 2010 la Unión Europea se convirtiese en la economía basada en el conocimiento más competitiva y dinámica del mundo, capaz de crecer económicamente de manera sostenible con más y mejores empleos y con mayor cohesión social», pero respetando el medio ambiente. En esta declaración subyace la constatación de que, para mejorar su nivel de vida y mantener su modelo social único, se debía aumentar su productividad y competitividad frente a una competencia global cada vez más fuerte, el cambio tecnológico y el envejecimiento de la población. Y se reconocía que la agenda de reformas no podía llevarse a cabo solo en el ámbito europeo, porque como muchas áreas implicaban competencias de los Estados miembros, sería necesaria una estre-

OCDE, Employment Outlook, 2009. Tackling the jobs crisis, págs.61 ss.

OIT, "Proteger a las personas y promover el empleo. Un estudio de las respuestas de los países ante la crisis económica mundial en la esfera de las políticas de empleo y de protección social", septiembre de 2009, págs. 46 y ss. 
cha colaboración entre éstos y la Unión Europea para obtener resultados. También se reconoció por primera vez que las economías de los Estados miembros están intrínsecamente ligadas y que la acción (o falta de acción) de un Estado miembro podría tener consecuencias significativas para la Unión Europea en conjunto.

No obstante, la Estrategia original evolucionó gradualmente hacia una estructura excesivamente compleja con objetivos y acciones múltiples y una división confusa de las responsabilidades y tareas, particularmente entre la Unión Europea y el nivel nacional. Por ello, la Estrategia de Lisboa se relanzó en 2005 tras una revisión intermedia. A fin de tener un mayor sentido de las prioridades, la Estrategia relanzada se centró en el crecimiento y el empleo, estableciéndose una nueva estructura de gobernanza basada en un enfoque de asociación entre los Estados miembros y las instituciones de la Unión Europea.

En conjunto, se constata que la Estrategia de Lisboa ha tenido un impacto positivo en la Unión Europea, aunque no se hayan alcanzado sus objetivos principales (es decir, un nivel de empleo del $70 \%$ y un gasto en I+D del $3 \%$ del PIB). El nivel de empleo de la Unión Europa alcanzó el $66 \%$ en 2008 (frente al $62 \%$ de 2000), antes de volver a caer a consecuencia de la crisis. Sin embargo, no ha logrado superar el desfase de incremento de la productividad con respecto a los principales países industrializados: el gasto total en I+D en la UE, expresado como porcentaje del PIB, apenas mejoró marginalmente (del 1,82 \% en 2000 al 1,9 \% en 2008). Sin embargo, sería demasiado simplista concluir que la Estrategia fracasó por no haber alcanzado estos objetivos; es más, la Estrategia ha abierto nuevas vías al promover acciones comunes para abordar los principales retos a largo plazo de la Unión Europea ${ }^{8}$.

Sin embargo, los vínculos entre la Estrategia de Lisboa y otros instrumentos o estrategias de la Unión Europea, como el Pacto de Estabilidad y Crecimiento, la Estrategia de Desarrollo Sostenible o la Agenda Social, no han sido suficientemente fuertes, de manera que en vez de reforzarse mutuamente, parte de las estrategias han actuado de forma aislada.

Finalmente, el Consejo Europeo de junio de 2010 adoptó la nueva Estrategia de Empleo Europa 2020, estableciendo un nuevo ciclo de diez años que se extiende hasta el año 2020, a partir de un conjunto de diez directrices orientadas a alcanzar un "crecimiento sostenible".

Comisión Europea, Documento de Evaluación de la Estrategia de Lisboa, 2 de febrero de 20 2010. SEC(2010) 114 final.

http://ec.europa.eu/social/main.jsp?catId=101\&langId=es. 


\begin{tabular}{|c|c|}
\hline \multicolumn{2}{|r|}{ Directrices } \\
\hline Directriz 1 & $\begin{array}{l}\text { Garantizar la calidad y la viabilidad de las finanzas públi- } \\
\text { cas }\end{array}$ \\
\hline Directriz 2 & Abordar los desequilibrios macroeconómicos \\
\hline Directriz 3 & Reducir los desequilibrios dentro de la zona del euro \\
\hline Directriz 4 & $\begin{array}{l}\text { Optimizar el apoyo a la investigación, el desarrollo y la in- } \\
\text { novación }(\mathrm{I}+\mathrm{D}+\mathrm{i}) \text {, reforzar el «triángulo del conocimiento» } \\
\text { y liberar el potencial de la economía digital }\end{array}$ \\
\hline Directriz 5 & $\begin{array}{l}\text { Mejorar la utilización eficiente de los recursos y reducir los } \\
\text { gases de efecto invernadero }\end{array}$ \\
\hline Directriz 6 & $\begin{array}{l}\text { Mejorar el entorno empresarial y de los consumidores, } \\
\text { y modernizar y desarrollar la base industrial para garantizar } \\
\text { el pleno funcionamiento del mercado interior }\end{array}$ \\
\hline Directriz 7 & $\begin{array}{l}\text { Aumentar la participación de mujeres y hombres en el mer- } \\
\text { cado laboral, reducir el desempleo estructural y fomentar el } \\
\text { empleo de calidad }\end{array}$ \\
\hline Directriz 8 & $\begin{array}{l}\text { Conseguir una población activa cualificada que responda } \\
\text { a las necesidades del mercado laboral, y promover el apren- } \\
\text { dizaje permanente }\end{array}$ \\
\hline Directriz 9 & $\begin{array}{l}\text { Mejorar la calidad y los resultados de los sistemas educa- } \\
\text { tivos y de formación en todos los niveles, e incrementar la } \\
\text { participación en la enseñanza superior o equivalente }\end{array}$ \\
\hline Directriz 10 & Promover la inclusión social y luchar contra la pobreza \\
\hline
\end{tabular}

El Consejo Europeo ha adoptado cinco objetivos comunes quehan de orientar la actuación delos Estados miembros y de la Unión en relación con el fomento del empleo, la mejora de las condiciones para la innovación, la investigación y el desarrollo, el cumplimiento de los objetivos de cambio climático y energía, la mejora de los niveles educativos y el fomento de la integración social reduciendo la pobreza.

La Estrategia Europea de Empleo proporciona un marco, denominado método abierto de coordinación ${ }^{10}$, que permite a los países de la Unión Europea compartir información, debatir sus políticas de empleo y coordinarlas. nation_es.htm.

http: / / europa.eu/legislation_summaries/glossary/open_method_coordi- 
Se fundamenta en el estudio prospectivo anual sobre el crecimiento ${ }^{11}$, que establece las prioridades para el año siguiente de la Unión Europea destinadas a impulsar el crecimiento y la creación de empleo y abre el semestre europeo anual, que promueve la coordinación de las políticas económicas y fiscales de los gobiernos nacionales.

Cada año, este proceso, apoyado por la labor del comité de empleo, consta de las siguientes fases:

$\checkmark \quad$ Directrices de empleo: prioridades y objetivos comunes de las políticas de empleo. Propuestas por la Comisión, acordadas por los gobiernos nacionales y adoptados por el Consejo de la Unión Europea.

$\checkmark \quad$ Informe conjunto sobre empleo: se basa en una evaluación de la situación del empleo en Europa, en la aplicación de las Directrices de empleo y en el estudio de los proyectos de programas nacionales de reforma por el Comité de Empleo. Forma parte del Estudio prospectivo anual sobre el crecimiento, lo publica la Comisión y lo adopta el Consejo de la Unión Europea.

$\checkmark \quad$ Programas nacionales de reforma: presentados por los gobiernos nacionales, la Comisión analiza su adecuación a Europa $2020^{12}$.

$\checkmark \quad$ Recomendaciones específicas para cada país: elaboradas por la Comisión y basadas en la evaluación de los programas nacionales de refor$\mathrm{ma}^{13}$.

La Estrategia Europea de Empleo se basa también en la Agenda de nuevas cualificaciones y empleos de Europa $2020^{14}$ y cuenta con el apoyo del Observatorio Europeo del Empleo ${ }^{15}$ y el Programa de Enseñanza Mutua ${ }^{16}$.

\section{El mercado de trabajo dual en España}

La dualidad en el mercado de trabajo, especialmente en el caso español, requiere una clara simplificación contractual. Esta necesidad está claramente relacionada con la calidad del mercado de trabajo español. A la vista i) de la exorbitante

http: / / ec.europa.eu/europe2020/making-it-happen/annual-growth-surveys/index_en.htm.

http: / / www.mineco.gob.es/stfls / mineco/prensa/noticias / 2014/Programa_Reformas_2014.pdf.

http:/ / ec.europa.eu/europe2020/index_es.htm\#map.

http://ec.europa.eu/social/main.jsp?langId=es\&catId=958.

http://www.eu-employment-observatory.net/.

http:/ / ec.europa.eu/social/main.jsp?catId=1047\&langId=en . 
tasa de paro, ii) de la segmentación entre trabajadores fijos sobreprotegidos, trabajadores temporales definitivos y trabajadores en la economía sumergida, y iii) de la evolución disparatada de los salarios durante la burbuja económica anterior a la crisis, cabe sospechar que las relaciones laborales españolas, por lo menos hasta la reciente reforma, han carecido de capacidad de adaptación al resto de condiciones económicas y empresariales.

El mercado de trabajo de España se adorna con otras limitaciones igualmente sustanciales, como: a) inmovilidad territorial entre regiones y entre países de la Unión Europea, b) negociación colectiva que separa los salarios de la dinámica de la productividad, c) inadecuada calificación de la fuerza de trabajo, con déficits severos en el sistema educativo y la formación profesional, d) no sostenibilidad del sistema de seguridad social, y e) tendencias centrífugas en la administración, que magnifican el gasto público.

Estos elementos han conducido a una tormenta perfecta. Han venido a coincidir los retos de medio plazo sobre la competitividad con retos financieros inmediatos, un exceso de regulación nacional con la competencia global, y la crisis económica con la inestabilidad institucional. Las características del mercado de trabajo español suponen un lastre esencial a la competitividad que requiere el formar parte de una unión monetaria. Aunque la solución al paro y a los problemas del mercado de trabajo no vendrá sólo del cambio institucional que liberalice las relaciones laborales, ésta es una condición sine qua non de la recuperación económica.

Esta realidad aún es más patente si, con la ayuda de las fuentes españolas e internacionales, se comparan los principales aspectos del mercado de trabajo de España con la situación en los países de la Unión Europea. Por ello, la evaluación de la calidad del mercado de trabajo español pretende contribuir a reforzar la capacidad reformadora de los agentes sociales.

Hay que tener en cuenta que el día 12 de febrero de 2012, entró en vigor en España el Real Decreto-ley 3/2012, de medidas urgentes para la reforma del mercado laboral, que tras su tramitación parlamentaria dio lugar a la Ley 3/2012, de 6 de julio; se trata de la primera norma que constituye la denominada "Reforma Laboral", aunque hay aspectos que sufrieron importantes cambios en el año 2011, como la negociación colectiva o la Seguridad Social y se han ido promulgando normas hasta la actualidad, por lo que difícilmente se puede afirmar que el camino ha sido completado. Asimismo, y aunque no tuviera vocación de fomentar dicha reforma, pero por la importancia que ha tenido, hay que destacar el II Acuerdo de Empleo y Negociación Colectiva, suscrito por los interlocutores sociales el 25 de enero de $2012^{17}$.

Sin embargo, no han existido reformas concretas que hayan tenido como objetivo la simplificación contractual. De hecho, se ha producido, fenómeno que se inició en el año 1984 de manera generalizada, un efecto de multiplicación del que no se ha sido totalmente consciente. La razón es simple. Es difícil conocer cuántas

http:/ /www.boe.es/boe/dias/2012/02/06/pdfs /BOE-A-2012-1778.pdf. 
modalidades contractuales existen en la actualidad y cuál es su régimen jurídico ${ }^{18}$.

Es más, se puede apuntar la siguiente circunstancia. Si se comparan los modelos de contratos existentes en España, al menos los que pueden ser calificados como tradicionales, con los regulados en los países de nuestro entorno en la Unión Europea se advierte que en cuanto a modelos, las diferencias son muy limitadas. Así, por ejemplo, la regulación del contrato de obra o servicio determinado, con el nombre que se le haya otorgado en cada país, es muy similar en los países miembros.

Entonces, ¿cómo entender que con situaciones económicas similares, no las actuales, y con regulaciones parecidas, los índices de temporalidad en España sean el triple que la media de la Unión Europea y multipliquen por varios números los datos de algunos países en concreto, como por ejemplo, Alemania o los Países Bajos?

En la actualidad, cuando hablamos de modalidades contractuales, hay una clasificación inicial a tener en cuenta, según cuál sea la duración del contrato de trabajo. En principio los contratos pueden ser diferenciados entre los denominados indefinidos y los de duración determinada. A su vez, caben diversas modalidades según se esté ante contratos de una u otra opción en los que cabe algún tipo de bonificación o reducción de cuotas a la Seguridad Social. De la misma manera, entre los contratos de duración determinada hay diversas modalidades, entre los que destacan los contratos formativos y los contratos de duración determinada por la concurrencia de determinadas causas.

Además, el mercado de de trabajo español está extraordinariamente desequilibrado, ya que hay unos 5 millones de parados. Las razones de esta situación son diversas, pero la mayor parte muy claras. El mercado de trabajo en España no tiene flexibilidad en precios (salarios no bajan) ni en movilidad (no van trabajadores a Europa, la emigración es realmente exigua).

Luego, al no poder el mercado equilibrarse a través de los precios (salarios) y de la movilidad (migración), el mercado se "equilibra" a través de las cantidades de personas que pueden entrar y salir del mercado de trabajo a través del desempleo, ya sea por medio de mecanismos de protección formal, como la prestación de desempleo contributiva, la prestación de desempleo asistencial o los diversos mecanismos incluidos en el concepto de asistencia social.

Estas son, probablemente, las razones que explican que en España haya una tasa de paro del $26 \%$ y en Alemania del $5 \%$, como se puede observar en el siguiente gráfico.

http://www.sepe.es/contenidos/que_es_el_sepe/publicaciones/pdf/pdf_ empleo/guia_contratos.pdf 


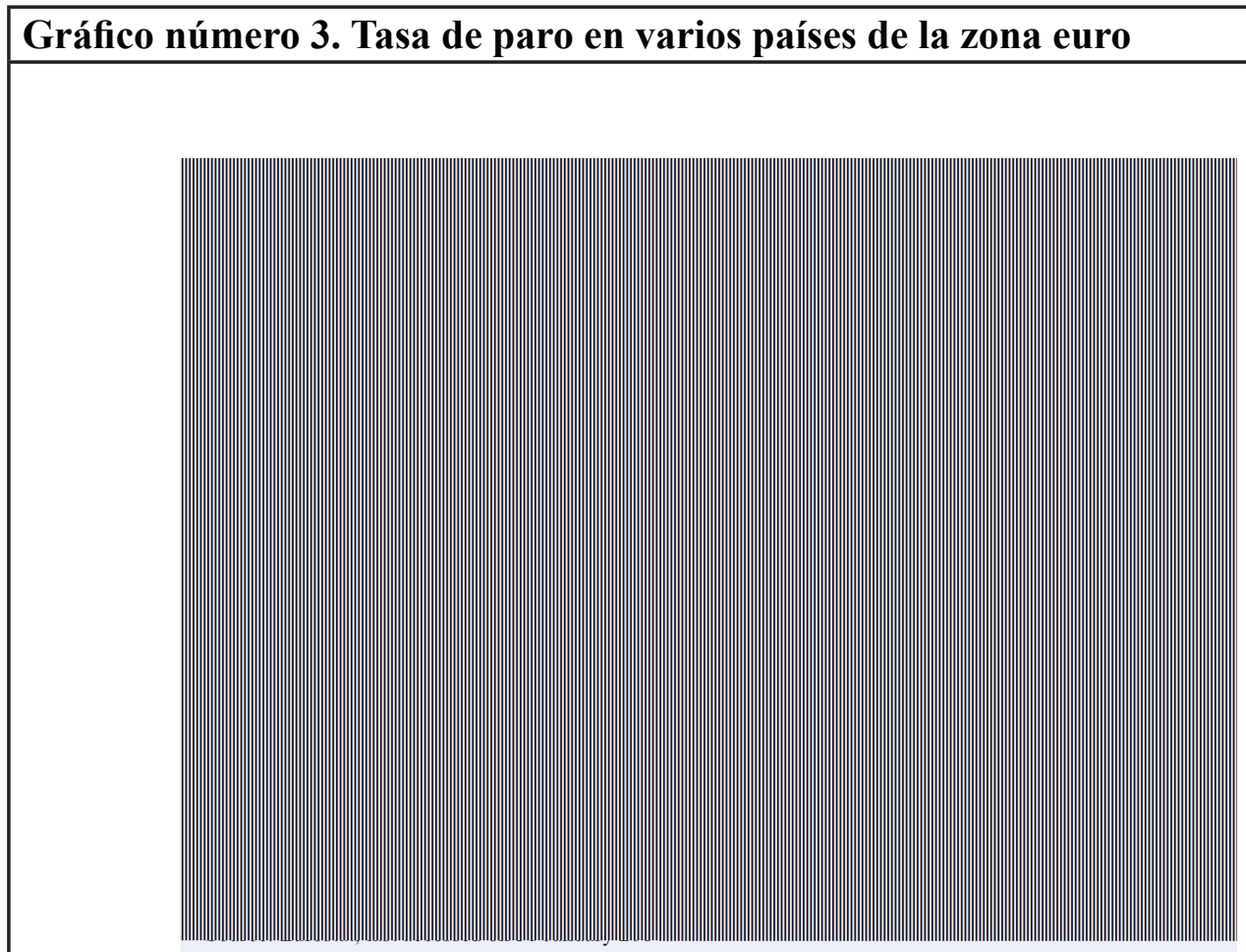

De la misma manera, si se analiza la evolución del empleo, los países anglosajones (Australia, Canadá, Reino Unido y EEUU) y alguna economía emergente (México) son los que han mantenido un crecimiento del empleo más constante a partir del año 2010.Sin embargo, Portugal, Irlanda, Grecia y España (PIGS), son los que mayor destrucción de empleo han generado, encadenando hasta 5 años consecutivos de elevados porcentajes de decrecimientos. 


\begin{tabular}{|c|c|c|c|c|c|c|c|c|c|}
\hline \multicolumn{10}{|c|}{$\begin{array}{l}\text { Annex Table 20. Employment } \\
\text { Percentage change from previous period }\end{array}$} \\
\hline & \multicolumn{9}{|c|}{ Employment } \\
\hline & $\begin{array}{l}\text { Average } \\
1989-98\end{array}$ & $\begin{array}{l}\text { Average } \\
1999-08\end{array}$ & 2009 & 2010 & 2011 & 2012 & 2013 & 2014 & 2015 \\
\hline Australia & 1,1 & 2,0 & 0,7 & 2,0 & 1,7 & 1,2 & 1,0 & 0,7 & 1,7 \\
\hline Austria & 1,1 & 0,6 & $-0,2$ & 0,5 & 1,2 & 0,9 & $-0,2$ & 0,8 & 1,4 \\
\hline Belgium & 0,4 & 0,9 & $-0,2$ & 0,7 & 1,4 & 0,2 & $-0,2$ & 0,6 & 1,0 \\
\hline Canada & 0,9 & 1,9 & $-1,6$ & 1,4 & 1,5 & 1,2 & 1,3 & 0,9 & 1,3 \\
\hline Czech Republic & .. & $-0,1$ & $-1,4$ & $-1,0$ & $-0,2$ & 0,4 & 1,0 & 0,2 & 0,3 \\
\hline Denmark & 0,2 & 0,5 & $-2,9$ & $-2,3$ & $-0,1$ & $-0,5$ & 0,0 & 0,3 & 0,5 \\
\hline Estonia & .. & .. & $-9,2$ & $-4,2$ & 6,8 & 2,5 & $-0,6$ & $-1,0$ & 0,5 \\
\hline Finland & $-1,2$ & 1,3 & $-2,9$ & $-0,4$ & 1,1 & 0,4 & $-1,1$ & $-0,3$ & 0,3 \\
\hline France & 0,1 & 0,9 & $-0,9$ & 0,3 & 0,2 & 0,0 & $-0,1$ & 0,2 & 0,6 \\
\hline Germany & 0,3 & 0,2 & $-0,3$ & 0,8 & 2,3 & 1,0 & 1,0 & 0,6 & 0,4 \\
\hline Greece & 1,0 & 1,4 & $-1,1$ & $-2,7$ & $-6,8$ & $-8,0$ & $-4,0$ & $-0,8$ & 1,3 \\
\hline Hungary & .. & 0,7 & $-2,5$ & 0,0 & 0,8 & 1,7 & 1,6 & 2,6 & $-0,1$ \\
\hline Iceland & 0,9 & 1,6 & $-6,2$ & $-0,3$ & 0,0 & 1,1 & 3,4 & 2,0 & 1,9 \\
\hline Ireland & 3,5 & 4,2 & $-6,6$ & $-4,1$ & $-1,8$ & $-0,6$ & 2,3 & 2,2 & 1,7 \\
\hline Israel & .. & 2,6 & 2,0 & 3,5 & 3,0 & 3,2 & 2,7 & 2,5 & 2,5 \\
\hline Italy & $-0,4$ & 0,7 & $-1,5$ & $-0,6$ & 0,3 & $-0,3$ & $-2,0$ & $-0,8$ & 0,4 \\
\hline Japan & 0,7 & $-0,1$ & $-1,5$ & $-0,3$ & $-0,1$ & $-0,3$ & 0,7 & 0,1 & $-0,1$ \\
\hline Korea & 1,4 & 1,4 & $-0,3$ & 1,4 & 1,7 & 1,8 & 1,6 & 1,8 & 1,6 \\
\hline Luxembourg & 1,0 & 1,7 & 1,0 & 1,7 & 2,7 & 2,4 & 1,8 & 2,2 & 2,3 \\
\hline Mexico & .. & 2,2 & 0,5 & 1,1 & 2,2 & 3,3 & 1,1 & 2,7 & 2,4 \\
\hline Netherlands & 2,0 & 1,5 & $-0,6$ & $-0,4$ & 0,6 & $-0,2$ & $-1,0$ & $-0,7$ & 0,5 \\
\hline New Zealand & 1,5 & 2,2 & $-1,5$ & 0,7 & 1,6 & 0,5 & 1,6 & 2,1 & 1,4 \\
\hline Norway & 1,0 & 1,2 & $-0,6$ & 0,1 & 1,4 & 2,0 & 0,6 & 1,0 & 1,2 \\
\hline Poland & .. & $-0,4$ & 0,4 & 0,6 & 0,6 & 0,2 & $-0,1$ & 0,8 & 0,4 \\
\hline Portugal & 0,9 & 0,9 & $-2,8$ & $-1,5$ & $-2,8$ & $-4,2$ & $-2,6$ & 1,3 & 0,9 \\
\hline Slovak Republic & .. & 0,5 & $-2,8$ & $-2,0$ & $-0,1$ & 0,6 & 0,0 & 0,2 & 0,7 \\
\hline Slovenia & .. & 1,3 & $-1,5$ & $-1,5$ & $-3,1$ & $-1,3$ & $-1,9$ & $-0,7$ & 0,0 \\
\hline Spain & 1,1 & 3,6 & $-6,8$ & $-2,3$ & $-1,9$ & $-4,5$ & $-3,1$ & 0,3 & 0,8 \\
\hline Sweden & $-1,2$ & 0,7 & $-2,1$ & 0,5 & 2,3 & 0,6 & 1,1 & 1,1 & 1,2 \\
\hline Switzerland & 0,6 & 0,6 & 0,4 & 0,4 & 2,2 & 1,2 & 1,1 & 1,7 & 1,6 \\
\hline United Kingdom & 0,0 & 1,0 & $-1,6$ & 0,2 & 0,5 & 1,2 & 1,3 & 1,8 & 1,2 \\
\hline United States & 1,3 & 1,3 & $-3,8$ & $-0,6$ & 0,6 & 1,8 & 1,0 & 1,6 & 1,6 \\
\hline Euro area & 0,4 & 1,1 & $-1,9$ & $-0,4$ & 0,3 & $-0,7$ & $-0,7$ & 0,2 & 0,6 \\
\hline Total OECD & 0,0 & 1,0 & $-1,8$ & 0,3 & 1,0 & 1,0 & 0,7 & 1,1 & 1,2 \\
\hline
\end{tabular}

Sxronze: DECD Economic Dutlook 95 database.

Además, hay que tener en cuenta que hay dos hitos temporales relevantes en los que se destruye más empleo: 2009, España fue el segundo país, tras Estonia y 2012, España fue el segundo país, tras Grecia, siendo seguido por Portugal (ambos intervenidos por la Unión Europea). Igualmente, hay que tener en cuenta que España fue el país cuyo empleo más disminuyó durante el periodo 2009-2013, pero, contraste, fue el segundo país, tras Irlanda, cuyo empleo más creció en el periodo 1998-2008.

Hay que tener en cuenta que en la Zona Euro, desde el 2010 hasta el 2015, el empleo se mantendrá prácticamente estable. En el 2015, la previsión es que España continuará estando entre el grupo de países que menos empleo creará en término relativos, si bien no destruirá el mismo, con porcentajes por debajo de la media de los países de la OCDE y de la Zona Euro. 


\begin{tabular}{|c|c|c|c|c|c|c|c|c|c|c|c|}
\hline \multicolumn{12}{|l|}{ Ocupados } \\
\hline \multicolumn{12}{|c|}{ Unidad: Miles de personas } \\
\hline Años & UE-28* & EA-18 & España & Alemania & Francia & Italia & Reino Unido & Países Bajos & Finlandia & Suecia & EEUU \\
\hline 1999 & $202.356,8$ & $127.824,4$ & $14.689,8$ & $36.281,4$ & $22.738,2$ & $20.691,6$ & $27.590,9$ & $7.702,1$ & $2.297,5$ & $4.148,8$ & $133.500,9$ \\
\hline 2000 & $204.053,8$ & $130.333,3$ & $15.505,9$ & $36.466,4$ & $23.331,2$ & $21.079,8$ & $27.365,7$ & $7.870,2$ & $2.336,3$ & $4.240,3$ & $136.900,7$ \\
\hline 2001 & $206.016,8$ & $132.385,7$ & $16.146,3$ & $36.572,9$ & $23.755,6$ & $21.514,4$ & $27.625,7$ & $8.068,7$ & $2.367,0$ & $4.318,1$ & $136.939,3$ \\
\hline 2002 & $205.862,1$ & $133.362,5$ & $16.630,3$ & $36.289,3$ & $23.943,6$ & $21.829,3$ & $27.808,4$ & $8.168,0$ & $2.372,3$ & $4.323,9$ & $136.480,9$ \\
\hline 2003 & $207.137,1$ & $134.843,9$ & $17.295,9$ & $35.924,9$ & $24.692,2$ & $22.054,2$ & $28.073,0$ & $8.121,4$ & $2.364,9$ & $4.314,4$ & $137.729,3$ \\
\hline 2004 & $208.842,7$ & $136.039,3$ & $17.970,8$ & $35.841,0$ & $24.768,4$ & $22.404,4$ & $28.369,4$ & $8.105,8$ & $2.364,6$ & $4.290,0$ & $139.239,8$ \\
\hline 2005 & $212.050,4$ & $138.360,5$ & $18.973,2$ & $36.361,6$ & $24.952,0$ & $22.562,8$ & $28.666,4$ & $8.110,9$ & $2.400,8$ & $4.346,7$ & $141.710,1$ \\
\hline 2006 & $216.275,7$ & $141.271,4$ & $19.747,7$ & $37.172,3$ & $25.110,1$ & $22.988,2$ & $28.931,3$ & $8.260,9$ & $2.443,5$ & $4.429,4$ & $144.417,6$ \\
\hline 2007 & $220.352,6$ & $144.129,9$ & $20.356,0$ & $37.988,7$ & $25.550,7$ & $23.221,8$ & $29.117,8$ & $8.463,5$ & $2.491,6$ & $4.540,7$ & $146.050,2$ \\
\hline 2008 & $222.846,7$ & $145.562,9$ & $20.257,6$ & $38.541,5$ & $25.885,1$ & $23.404,7$ & $29.363,9$ & $8.592,7$ & $2.530,9$ & $4.593,0$ & $145.373,3$ \\
\hline 2009 & $218.976,6$ & $142.780,2$ & $18.888,0$ & $38.471,1$ & $25.633,6$ & $23.025,0$ & $28.922,7$ & $8.596,1$ & $2.457,3$ & $4.499,3$ & $139.893,9$ \\
\hline 2010 & $217.359,5$ & $141.967,5$ & $18.456,5$ & $38.737,8$ & $25.673,4$ & $22.872,3$ & $28.941,5$ & $8.370,2$ & $2.447,5$ & $4.523,7$ & $139.076,0$ \\
\hline 2011 & $217.837,1$ & $142.335,0$ & $18.104,6$ & $39.737,1$ & $25.740,1$ & $22.967,2$ & $29.077,7$ & $8.368,7$ & $2.473,7$ & $4.625,9$ & $139.879,0$ \\
\hline 2012 & $217.457,8$ & $141.406,9$ & $17.282,0$ & $40.080,0$ & $25.745,6$ & $22.898,7$ & $29.428,1$ & $8.424,2$ & $2.483,2$ & $4.657,1$ & $142.465,7$ \\
\hline 2013 & $216.963,5$ & $140.441,9$ & $16.750,0$ & $40.450,1$ & $25.745,2$ & $22.420,3$ & $29.820,7$ & $8.364,8$ & $2.456,7$ & $4.704,5$ & $143.929,9$ \\
\hline \multicolumn{12}{|c|}{ Diferencia en miles de personas } \\
\hline $2000-2008$ & $18.792,9$ & $15.229,6$ & $4.751,7$ & $2.075,1$ & $2.553,9$ & $2.324,9$ & $1.998,2$ & 722,5 & 194,6 & 352,7 & $8.472,6$ \\
\hline 2009-2013 & $-2.013,1$ & $-2.338,3$ & $-2.138,0$ & $1.979,0$ & 111,6 & $-604,7$ & 898,0 & $-231,3$ & $-0,6$ & 205,2 & $4.036,0$ \\
\hline $2000-2013$ & $12.909,7$ & $10.108,6$ & $1.244,1$ & $3.983,7$ & $2.414,0$ & $1.340,5$ & $2.455,0$ & 494,6 & 120,4 & 464,2 & $7.029,3$ \\
\hline
\end{tabular}

En conclusión, desde el año 2008, España es el país con la tasa de paro más alta de los países de la OCDE, sólo siendo superada por Grecia en el año 2013, situación que se prevé se mantenga hasta, al menos, el 2015. Nuevamente, Portugal, Irlanda, Grecia y España (PIGS), a los que se les une Eslovaquia, son los que mayor desempleo han generado desde el año 2008. De la misma manera, los años 2009 y 2012 se consolidan como los años que más desempleo se generó, con incrementos sustanciales en las tasas de paro y en el 2013, los países con las tasas más bajas de desempleo fueron Corea, Noruega, Suiza, Austria y Alemania. 
Annex Table 13. Unemployment rates: commonly used definitions

Per cent of labour force

\begin{tabular}{|c|c|c|c|c|c|c|c|c|c|c|c|c|c|c|c|c|c|}
\hline $\begin{array}{l}2013 \\
\text { Unemployment } \\
\text { thousands }\end{array}$ & 2000 & 2001 & 2002 & 2003 & 2004 & 2005 & 2006 & 2007 & 2008 & 2009 & 2010 & 2011 & 2012 & 2013 & 2014 & 2015 & $\begin{array}{r}F( \\
2013\end{array}$ \\
\hline 687 & 6,3 & 6,7 & 6,4 & 5,9 & 5,4 & 5,0 & 4,8 & 4,4 & 4,2 & 5,6 & 5,2 & 5,1 & 5,2 & 5,7 & 6,1 & 6,0 & 5,8 \\
\hline 218 & 3,5 & 3,6 & 4,0 & 4,3 & 5,0 & 5,2 & 4,8 & 4,4 & 3,9 & 4,8 & 4,4 & 4,2 & 4,4 & 5,0 & 5,0 & 4,6 & 5,1 \\
\hline 423 & 7,0 & 6,7 & 7,6 & 8,2 & 8,3 & 8,4 & 8,2 & 7,5 & 7,1 & 7,9 & 8,3 & 7,2 & 7,6 & 8,4 & 8,4 & 8,2 & 8,4 \\
\hline 1350 & 6,8 & 7,3 & 7,7 & 7,6 & 7,2 & 6,7 & 6,3 & 6,0 & 6,1 & 8,3 & 8,0 & 7,5 & 7,3 & 7,1 & 6,9 & 6,6 & 7,0 \\
\hline 492 & 9,7 & 9,8 & 9,8 & 9,5 & 10,0 & 9,2 & 7,8 & 7,2 & 7,8 & 9,7 & 8,2 & 7,1 & 6,4 & 5,9 & 6,2 & 6,3 & 6,1 \\
\hline 369 & 8,8 & 8,2 & 7,3 & 7,8 & 8,3 & 7,9 & 7,1 & 5,3 & 4,4 & 6,7 & 7,3 & 6,7 & 7,0 & 6,9 & 6,9 & 6,8 & 6,8 \\
\hline 203 & 4,3 & 4,5 & 4,6 & 5,4 & 5,5 & 4,8 & 3,9 & 3,8 & 3,5 & 6,0 & 7,5 & 7,6 & 7,5 & 7,0 & 6,8 & 6,7 & 7,0 \\
\hline 59 & 13,6 & 12,6 & 10,3 & 10,0 & 9,7 & 7,9 & 5,9 & 4,6 & 5,6 & 13,9 & 16,8 & 12,4 & 10,1 & 8,6 & 8,9 & 8,5 & 9,0 \\
\hline 219 & 9,8 & 9,1 & 9,1 & 9,0 & 8,8 & 8,4 & 7,7 & 6,9 & 6,4 & 8,3 & 8,4 & 7,8 & 7,7 & 8,2 & 8,4 & 8,4 & 8,5 \\
\hline 2826 & 8,2 & 7,4 & 7,5 & 8,2 & 8,5 & 8,5 & 8,5 & 7,7 & 7,1 & 8,8 & 8,9 & 8,8 & 9,4 & 9,9 & 9,9 & 9,8 & 9,8 \\
\hline 2251 & 8,0 & 7,9 & 8,7 & 9,8 & 10,5 & 11,3 & 10,2 & 8,7 & 7,5 & 7,8 & 7,1 & 6,0 & 5,5 & 5,3 & 5,0 & 4,9 & 5,1 \\
\hline 1354 & 11,4 & 10,8 & 10,3 & 9,7 & 10,5 & 9,8 & 8,9 & 8,3 & 7,7 & 9,5 & 12,5 & 17,7 & 24,2 & 27,3 & 27,1 & 26,7 & .. \\
\hline 448 & 6,4 & 5,7 & 5,8 & 5,9 & 6,1 & 7,2 & 7,5 & 7,4 & 7,9 & 10,0 & 11,1 & 10,9 & 11,0 & 10,2 & 8,7 & 8,9 & 9,4 \\
\hline 10 & 2,3 & 2,2 & 3,2 & 3,3 & 3,1 & 2,6 & 2,9 & 2,3 & 3,0 & 7,2 & 7,6 & 7,1 & 6,0 & 5,4 & 4,5 & 4,2 & 5,4 \\
\hline 282 & 4,3 & 3,9 & 4,4 & 4,7 & 4,5 & 4,3 & 4,4 & 4,6 & 6,0 & 12,0 & 13,9 & 14,6 & 14,7 & 13,0 & 11,4 & 10,4 & 12,0 \\
\hline 231 & 11,0 & 11,6 & 12,8 & 13,3 & 12,9 & 11,3 & 10,5 & 9,1 & 7,7 & 9,5 & 8,3 & 7,1 & 6,9 & 6,3 & 5,9 & 5,8 & 5,8 \\
\hline 3124 & 10,0 & 9,0 & 8,5 & 8,4 & 8,0 & 7,7 & 6,8 & 6,1 & 6,8 & 7,8 & 8,4 & 8,4 & 10,7 & 12,2 & 12,8 & 12,5 & 12,6 \\
\hline 2653 & 4,7 & 5,0 & 5,4 & 5,3 & 4,7 & 4,4 & 4,1 & 3,8 & 4,0 & 5,0 & 5,0 & 4,6 & 4,3 & 4,0 & 3,8 & 3,7 & 3,9 \\
\hline 806 & 4,4 & 4,0 & 3,3 & 3,6 & 3,7 & 3,7 & 3,5 & 3,2 & 3,2 & 3,7 & 3,7 & 3,4 & 3,2 & 3,1 & 3,1 & 3,0 & 3,0 \\
\hline 17 & 2,4 & 2,2 & 2,5 & 3,3 & 3,7 & 4,1 & 4,3 & 4,2 & 4,2 & 5,5 & 5,8 & 5,7 & 6,1 & 6,9 & 7,1 & 7,1 & 7,1 \\
\hline 2560 & 2,6 & 2,5 & 2,9 & 3,0 & 3,7 & 3,5 & 3,5 & 3,6 & 3,9 & 5,4 & 5,3 & 5,2 & 4,9 & 4,9 & 4,6 & 4,4 & 4,8 \\
\hline 600 & 2,9 & 2,4 & 3,0 & 4,0 & 4,9 & 5,1 & 4,2 & 3,5 & 3,0 & 3,7 & 4,4 & 4,3 & 5,2 & 6,6 & 7,6 & 7,6 & 7,0 \\
\hline 149 & 6,1 & 5,5 & 5,3 & 4,8 & 4,0 & 3,8 & 3,8 & 3,7 & 4,1 & 6,1 & 6,5 & 6,5 & 6,9 & 6,2 & 5,9 & 5,6 & 6,0 \\
\hline 92 & 3,3 & 3,5 & 3,7 & 4,0 & 4,2 & 4,4 & 3,4 & 2,5 & 2,6 & 3,1 & 3,5 & 3,2 & 3,1 & 3,4 & 3,5 & 3,5 & 3,5 \\
\hline 1793 & 16,1 & 18,3 & 20,0 & 19,7 & 19,0 & 17,8 & 13,9 & 9,6 & 7,1 & 8,2 & 9,6 & 9,6 & 10,1 & 10,3 & 9,8 & 9,5 & 9,9 \\
\hline 876 & 4,0 & 4,0 & 5,0 & 6,3 & 6,7 & 7,6 & 7,6 & 8,0 & 7,6 & 9,5 & 10,8 & 12,7 & 15,6 & 16,3 & 15,1 & 14,8 & 15,4 \\
\hline 386 & 18,8 & 19,3 & 18,6 & 17,5 & 18,1 & 16,2 & 13,3 & 11,0 & 9,6 & 12,1 & 14,4 & 13,6 & 13,9 & 14,2 & 13,9 & 13,2 & 14,1 \\
\hline 102 & 6,7 & 6,2 & 6,3 & 6,7 & 6,3 & 6,5 & 5,9 & 4,8 & 4,4 & 5,9 & 7,2 & 8,2 & 8,8 & 10,1 & 10,2 & 10,2 & 9,6 \\
\hline 5995 & 10,8 & 10,1 & 11,0 & 11,0 & 10,5 & 9,2 & 8,5 & 8,3 & 11,3 & 18,0 & 20,1 & 21,6 & 25,0 & 26,4 & 25,4 & 24,4 & 26,1 \\
\hline 410 & 6,7 & 5,8 & 6,0 & 6,6 & 7,4 & 7,7 & 7,1 & 6,1 & 6,2 & 8,3 & 8,6 & 7,8 & 8,0 & 8,0 & 7,9 & 7,4 & 8,0 \\
\hline 205 & 2,6 & 2,3 & 3,0 & 4,0 & 4,3 & 4,3 & 3,9 & 3,6 & 3,3 & 4,3 & 4,5 & 4,0 & 4,1 & 4,3 & 3,9 & 3,4 & 4,0 \\
\hline 2747 & 6,9 & 8,7 & 10,7 & 10,8 & 10,6 & 10,4 & 10,0 & 10,1 & 10,7 & 13,7 & 11,7 & 9,6 & 9,0 & 9,5 & 9,8 & 9,6 & .. \\
\hline 2460 & 5,5 & 5,1 & 5,2 & 5,0 & 4,8 & 4,9 & 5,5 & 5,4 & 5,7 & 7,6 & 7,9 & 8,1 & 7,9 & 7,6 & 6,9 & 6,5 & 7,2 \\
\hline 11449 & 4,0 & 4,8 & 5,8 & 6,0 & 5,5 & 5,1 & 4,6 & 4,6 & 5,8 & 9,3 & 9,6 & 8,9 & 8,1 & 7,4 & 6,5 & 6,0 & 7,0 \\
\hline 18732 & 8,4 & 7,9 & 8,3 & 8,8 & 9,0 & 9,0 & 8,3 & 7,4 & 7,5 & 9,4 & 10,0 & 10,0 & 11,2 & 11,9 & 11,7 & 11,4 & 11,8 \\
\hline 47844 & 6,0 & 6,2 & 6,8 & 7,0 & 6,9 & 6,6 & 6,1 & 5,6 & 6,0 & 8,1 & 8,3 & 7,9 & 7,9 & 7,9 & 7,5 & 7,2 & 7,7 \\
\hline
\end{tabular}

rket data are subject to differences in definitions across countries and to many breaks in series, though the latter are often of a minor nature. onal Employment Survey.

conomic Outlook 95 database.

A conclusiones similares se llega si se analizan los costes laborales comparados. El siguiente gráfico muestra los costes laborales unitarios en los países de la eurozona. La clave del mismo es evidente: con la burbuja, se perdió competitividad, se aumentó la dualidad en el mercado de trabajo y se produjo una transformación de la contratación como elemento de ajuste, y no de búsqueda de competitividad. Luego, lo que está haciendo la economía española, acompañada mejor o peor por la política económica, es volver a los niveles anteriores a la burbuja. Por tanto, queda muchísimos costes laborales unitarios por reducir, los salarios deberán bajar y bajar aún, por lo menos relativamente a Alemania. 


\section{Gráfico número 4. Costes laborales unitarios en varios países de la} zona euro

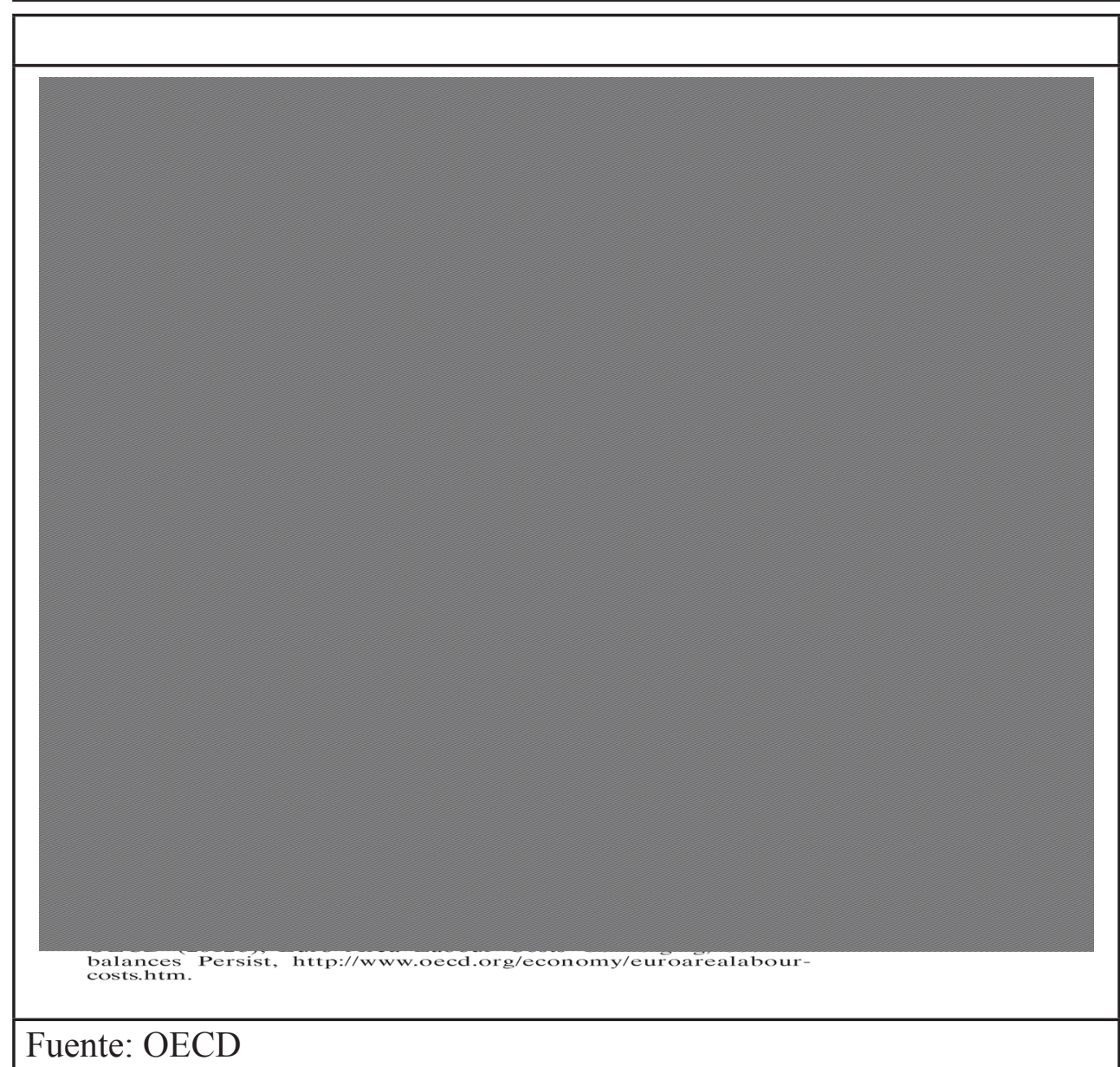

La reforma laboral española ha supuesto un paso sustancial en el proceso demodernización de la legislación, aproximándose a la flexibilidad (flexeguridad) de los países de nuestro entorno, que ya han realizado este tipo de reformas, pero es preciso seguir avanzado en algunos aspectos que han quedado pendientes.

Es imprescindible que la continuación de la reforma del mercado de trabajo se fundamenta, es cierto que también hay otros aspectos al menos igual de importantes, en tratar de eliminar la dualidad del mercado de trabajo existente, los protegidos y los débiles y que uno de los principales mecanismos para lograr este objetivo ha de ser la simplificación de las modalidades contractuales actuales, cuyo 
efecto está resultando muy negativo.

\section{La dualidad del mercado de trabajo}

La creación de empleo está siendo uno de los objetivos de la reforma. El ataque a la estructura perversa del mercado de trabajo español, con trabajadores con mayores derechos que otros, o de primera y segunda clase, que normalmente se refiere a la diferencia entre trabajadores con contrato indefinido y trabajadores con contrato temporal, es uno de los grandes retos.

Ahora bien, hay que tener en cuenta que este concepto de dualidad del mercado de trabajo en España está íntimamente integrado a nuestra estructura laboral, ya que está presente desde los primeros años de la crisis económica originada en los años setenta. En aquellos momentos, los porcentajes de trabajadores contratos indefinidos, y por tanto, con todos los derechos que otorgaban las diferentes normativas laborales, eran la gran mayoría. Es cierto que era posible la contratación temporal, pero eran muy poco usadas.

El recurso a la contratación de manera temporal, que ha originado este efecto de dualidad ha sido una de las medidas tradicionales que se ha venido utilizando para auto-regular el mercado de trabajo en momentos de crisis. Sin embargo, los resultados han sido y están siendo devastadores.

De hecho, en la actual crisis, las herramientas que se han puesto al servicio de la consecución de los objetivos que pretenden la salida de la crisis han sido diversas, desde todos los puntos de vista, con resultado, al menos hasta la fecha, limitados, $y$, por supuesto, insuficientes para erradicar esta dualidad.

De hecho, analizando datos recientes, tras el moderado descenso del paro registrado en febrero de 2014, el mes de marzo se ha saldado con una disminución más significativa del mismo, de hecho, la más intensa en este mes desde el año 2006. La caída del desempleo es aún más positiva si tenemos presente que el mes de marzo ha coincidido otros años, y no éste, con Semana Santa y sus efectos positivos en el empleo.

La cifra de paro registrado por los Servicios Públicos de Empleo en el mes de marzo ha descendido en 16.620 personas, en relación con el mes anterior, frente a los 4.979 desempleados menos en marzo de 2013, mes que coincidió además con Semana Santa.

El número de desempleados registrados en las Oficinas de los Servicios Públicos de Empleo se ha situado en4.795.866 personas, aunque si se contabiliza a aquéllos que son excluidos de las listas oficiales por encontrarse en alguna de las situaciones reguladas en la Orden de 11 de marzo de 1985 y en concreto por estar realizando cursos de formación o ser demandantes de empleo con "disponibilidad limitada" o con "demanda de empleo específica", el número de parados asciende a 5.339 .753 personas. 


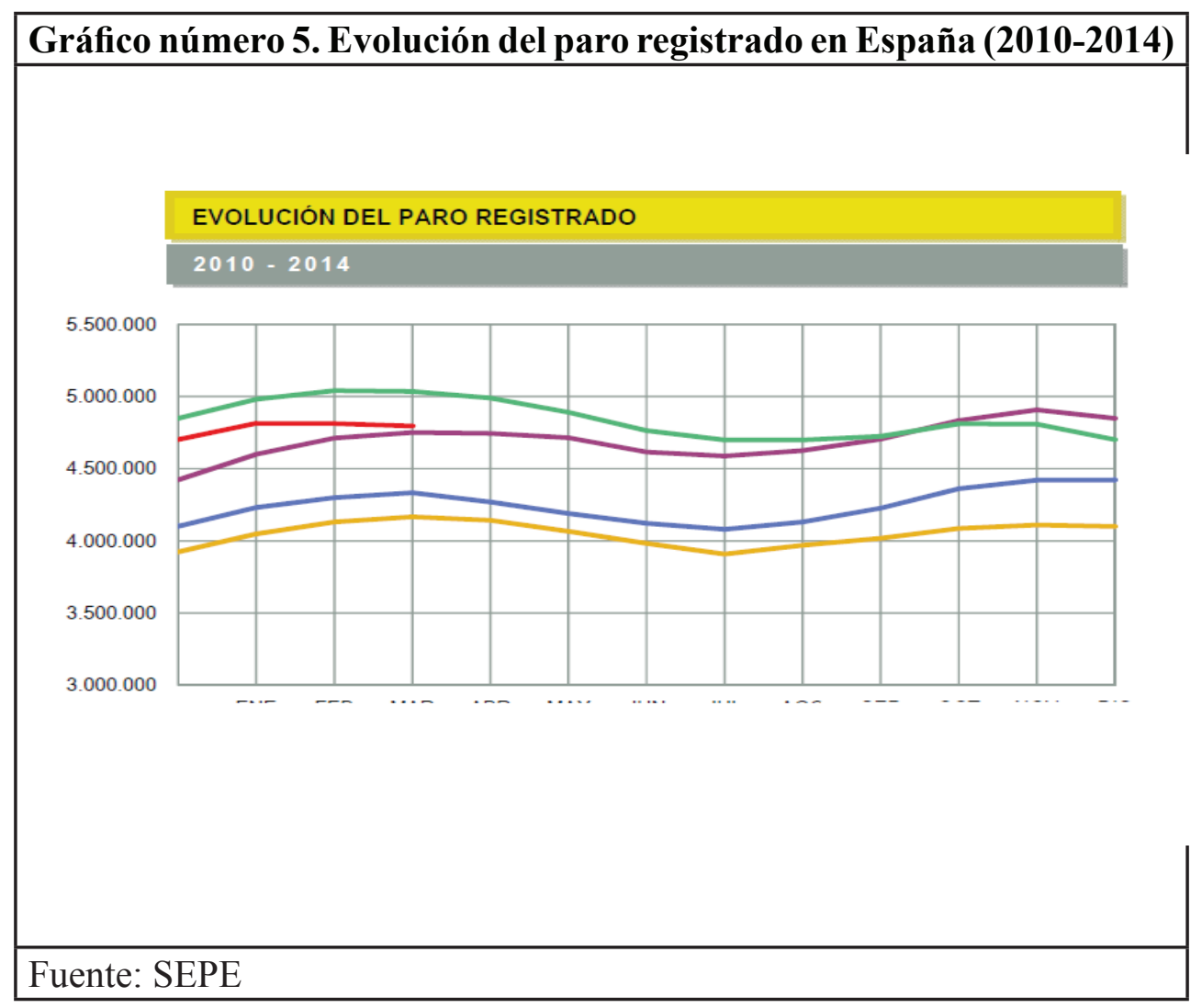

De esta manera, en términos interanuales el desempleo ha descendido en 239.377 personas (un 4,75\% interanual menos).

Por sectores de actividad económica, el paro desciende, especialmente en los servicios, seguido de construcción e industria. Por el contrario aumenta en la agricultura y en el colectivo sin empleo anterior.

Por sexo, el paro se ha reducido más entre los varones y se sitúa en 2.320.687, al bajar en 13.935 desempleados, aunque también desciende entre las mujeres con una cifra de 2.475.179 desempleadas.

Atendiendo al rango de edades, el descenso del desempleo alcanza sólo a los mayores de 25 años, teniendo en cuenta que en términos interanuales ha descendido en 48.027 personas $(10,01 \%)$.

Por comunidades autónomas, el desempleo ha disminuido en trece de ellas, destacando la Comunidad Valenciana con 5.902 parados menos, Cataluña $\mathbf{- 5 . 1 1 9}$ menos- y Galicia -3.608 menos-. Sin embargo crece en las cuatro comunidades restantes, encabezando la lista, por mayor incremento, Andalucía -10.060 desemplea- 
dos más- y País Vasco -2.112 más-.

El paro de los trabajadores extranjeros se situóen 580.761 personas, habiendo aumentado en 4.599 desempleados $(+0,80 \%)$ respecto al mes anterior y disminuido en 43.622 (-6,99\%) sobre el mismo mes de 2013.

Asimismo, en línea con los datos positivos de paro, los de afiliación a la Seguridad social, que son considerados de especial relevancia para analizar la evolución de nuestro mercado laboral, muestran el aumento respecto al mes anterior en 83.984 personas -en marzo de 2013 el incremento fue de 30.528 afiliados-, siendo el mejor dato de afiliación del mes de marzo desde 2007. Lo que nos sitúa en 16.296.288 afiliados. En términos interanuales la afiliación aumenta en 115.013 personas, con lo que se consolida la tasa interanual positiva $(0,71 \%)$.

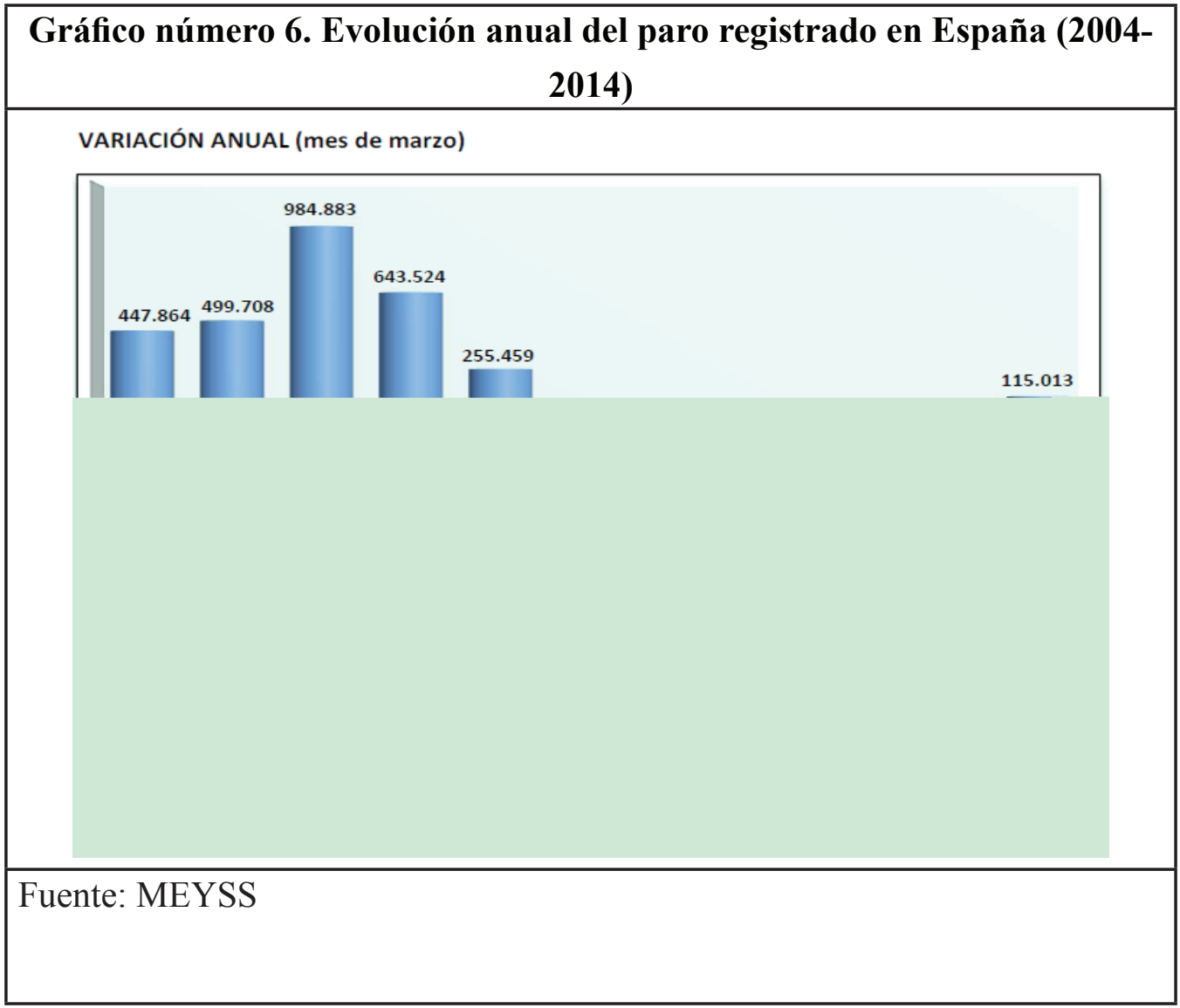

Los mayores crecimientos en términos interanuales, dentro del Régimen General de Seguridad Social, han tenido lugar en Educación (42.237); Hostelería (31.453); Actividades administrativas y servicios auxiliares (21.607); yActividades sanitarias y servicios sociales (11.942). Los retrocesos más significativos se registraron en Cons- 
trucción (-30.173); seguida de Actividades Financieras y de Seguros (-16.200); e Industria manufacturera (-10.806).

Por comunidades autónomas, en términos interanuales la afiliación registró aumentos en doce de ellas, siendo los más importantesen Andalucía (43.178 afiliados más), Cataluña (20.114 más) y Comunidad Valenciana (19.538 más).

Por sexo, el crecimiento de la afiliación en términos interanuales afectó más a las mujeres que suponen el 46,48\% de los afiliados (7.574.721), con un aumento interanual del $0,91 \%$. Por su parte, los varones representan el 53,52\% de los afiliados (8.721.567), con un incremento de la tasa interanual del $0,54 \%$.

La afiliación de extranjeros aumentó en marzo en 15.201 personas, respecto al mes anterior, y descendió en 68.249 sobre el mismo mes de 2013, registrando la cifra de 1.535 .889 afiliados extranjeros.

Como se puede observar, los datos están siendo positivos, ya que la recuperación económica está presente. Aún quedan aspectos a reformar, ya que existen ciertas disfunciones a resolver, especialmente las derivadas de un número importante de contrataciones mensuales que se ven reflejadas de una manera muy limitada en la cuantía de afiliaciones a la Seguridad Social. Este es uno de los aspectos más delicados de la actual coyuntura.

Sin embargo, en una primera impresión se puede constatar que si bien se están empezando a alcanzar número positivos en cuanto a la creación de empleo, no sólo se advierte el enorme esfuerzo que hay que realizar para consolidar estos datos, sino que la gran mayoría de los contratos que se formalizan en los últimos meses de 2013 y primeros meses de 2014 siguen siendo esencialmente temporales, por lo que el efecto de la dualidad del mercado de trabajo no sólo no desaparece, sino que se acrecienta, si se tiene en cuenta el crecimiento vegetativo negativo de los contratos indefinidos "tradicionales".

Hay que lograr crear empleo y que sea para todos los trabajadores igual, superando las diferencias de derechos entre los dos colectivos.

\subsection{La contratación indefinida}

El contrato de trabajo por tiempo indefinido ordinario es el prototipo en el Ordenamiento Jurídico español, al menos desde un punto de vista teórico. Se trata de un contrato muy sencillo de realizar, sin requisitos formales.

Sin embargo, no ha sido esta la modalidad contractual más utilizada, ni en la actualidad, ni en los últimos treinta años.

De hecho, si se analizan datos actuales, coincidiendo con el descenso del paro y el aumento de la afiliación a la Seguridad Social, las cifras totales del volumen de contratación siguen en la línea de suponer en marzo un aumento, respecto al mismo mes del año anterior, del 25,47\%, 247.010 contratos más. De esta forma el número de contratos registrados en marzo ha sido de 1.216.637. 


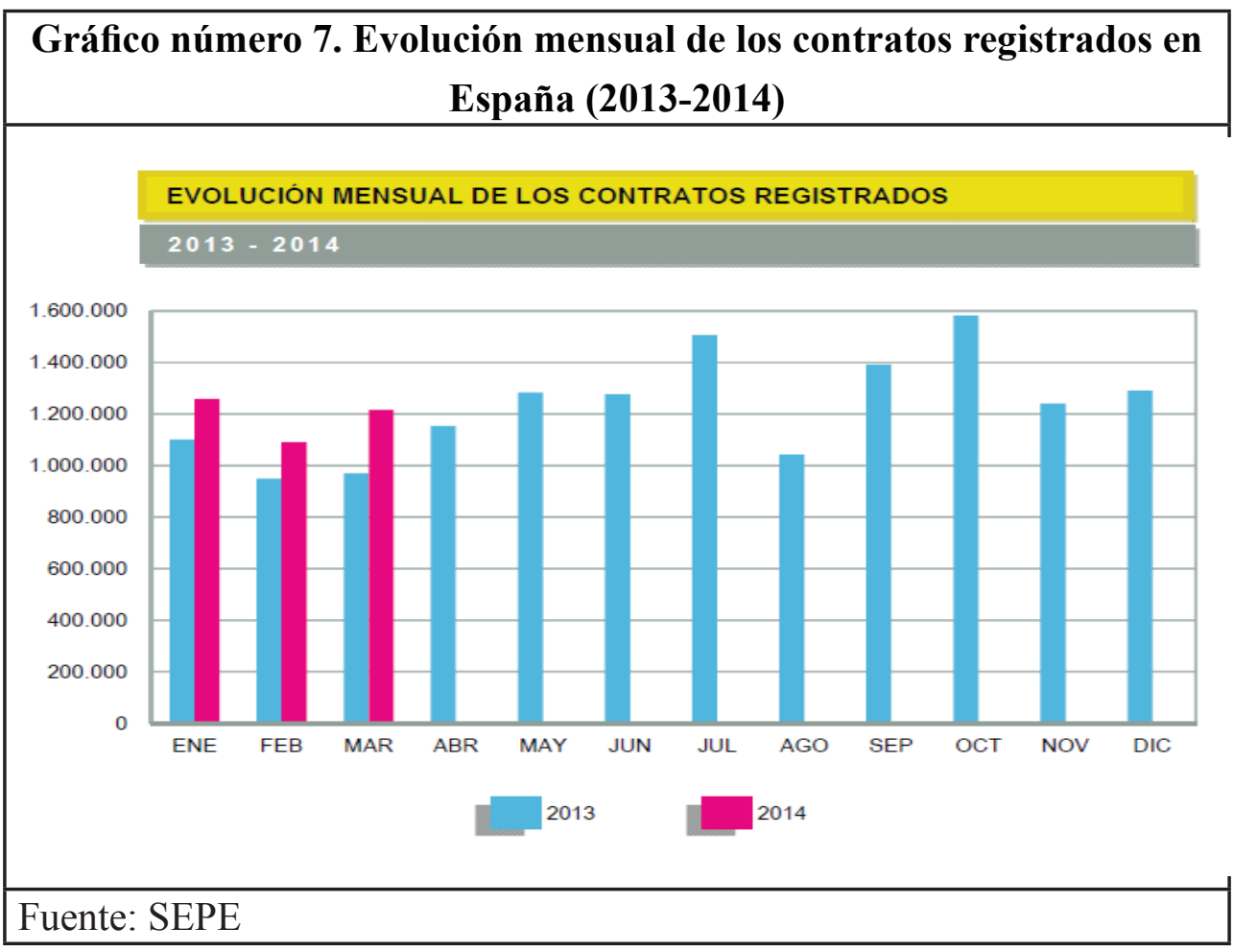

De hecho, del total de contratos, 113.481 fueron indefinidos -el 9,33\% del total de contratos registrados en dicho mes-, lo que implica un aumento del peso de la contratación indefinida y un incremento de 15.413 contratos indefinidos -el $15,72 \%$ - sobre el mismo mes del año anterior. Este incremento de los contratos indefinidos hace pensar que podríamos estar ante los primeros efectos de la reducción de las cotizaciones empresariales por contingencias comunes, derivados del Real Decreto-ley 3/2014, de 28 de febrero, de medidas urgentes para el fomento del empleo y la contratación indefinida.

Sobre el total de contratos indefinidos, 34.867 proceden de conversión de contratos temporales en fijos, el 30,72\% de los indefinidos registrados en marzo.

Además de esta modalidad general se pueden citar también las diversas modalidades de contratos indefinidos que presentan bonificaciones o reducciones de cuotas, entre los que citar, sin lleva a cabo valoraciones, ya que su efectividad aún no ha podido ser observada, los contratos bonificados para trabajadores en situación de exclusión social, los contratos bonificados para trabajadores en situación de exclusión social por empresas de inserción, los contratos de trabajo bonificados para trabajadores que tengan acreditada por la Administración competente la condición de víctima de violencia de género, doméstica o víctima del terrorismo, así como los 
contratos de trabajo para trabajadores mayores de 52 años beneficiarios de los subsidios por desempleo.

A diferencia de estas modalidades que no han tenido aún ninguna repercusión, hay dos tipos más que sí presentan efectos, aunque limitados.

En primer lugar, la Ley 3/2012, de 6 de julio, reguló el denominado contrato de trabajo indefinido de apoyo a los emprendedores. Se trata de un contrato de trabajo indefinido, a jornada completa y que presenta un período de duración de un año.

Para poder realizar este contrato, las empresas han de tener unas determinadas características, entre las que destaca por su importancia, el tener menos de 50 trabajadores en el momento de producirse la contratación. En este caso, la empresa podrá disfrutar de una serie de incentivos fiscales, vía impuesto de sociedades, así como bonificaciones en la cuota empresarial de la Seguridad Social durante 3 años, que serán diferentes según se trate de un trabajador joven (entre 16 a 30 años) o de un trabajador mayor de 45 años.

Los resultados se están observando, ya que desde el inicio de la posibilidad de suscripción de este contrato hasta el 30 de abril de 2014 se han formalizado 189.517contratos de este tipo, con un ritmo, aproximadamente, de unos 8.000 contratos al mes.

En relación a este contrato se ha de observar que se está consiguiendo, y este es un fenómeno reciente, una agravación del concepto de la dualidad, ya que no sólo se refiere a un diferente régimen jurídico entre trabajadores indefinidos y temporales, sino también entre empresas, según cual sea el número de trabajadores.

Además, el Real Decreto-ley 4/2013, de 22 de febrero, ha regulado tres modalidades de contratos, que aún no han sido incorporados al mercado de trabajo:

$\checkmark \quad$ Contrato indefinido de un joven por microempresas y empresarios autónomos.

$\checkmark \quad$ Contrato de nuevos proyectos de emprendimiento joven.

$\checkmark \quad$ Contrato a tiempo parcial con vinculación formativa.

En estos casos, de los que aún no existen datos de utilización por parte de las empresas, se continúa con la separación entre trabajadores de empresas con diferentes números de trabajadores, apoyando especialmente a un tipo de empresas muy concretas, los trabajadores autónomos, que se cree que puedan ser uno de los motores de la salida de la crisis.

\subsection{Los contratos temporales}

El Estatuto de los Trabajadores ha regulado tradicionalmente los denominados contratos temporales causales, a diferencia de una importante modalidad que se desarrolló durante los años 1984 hasta finales de los años noventa que se deno- 
minaba contrato de fomento y que sirvió para dar respuesta a las crisis económica española de los años ochenta.

En la actualidad, el art. 15 del Estatuto de los Trabajadores regula tres modalidades contractuales, en los que la ejecución del contrato debe concordar claramente con lo pactado, ha de concurrir la causa objetiva, con independencia de la voluntad de las partes y no basta la voluntad acorde de las partes en orden a la celebración del contrato, sino que ha de concurrir la causa objetiva específicamente prevista.

En cuanto a las modalidades contractuales cabe citar los siguientes supuestos:
$\checkmark \quad$ El contrato de obra o servicio determinado.
$\checkmark \quad$ El contrato eventual por circunstancias de la producción.
$\checkmark \quad$ El contrato de interinidad.

En cómputo general, hay que tener en cuenta que los contratos temporales registrados en el mes de marzo de 2014 ascendieron a 1.103.156, lo que nos sitúa en cifras un $26,57 \%$ superior a las del año anterior por las mismas fechas, en que se registraron 871.559 .

Las principales modalidades presentaron la siguiente evolución enmarzorespecto al mismo mes del año anterior: los eventuales -494.671- un aumento del 23,96\% sobre los 399.041 de marzo de 2013; los contratos deobra o servicio-482.804un crecimiento del $32,65 \%$ sobre 363.967 de marzo de 2013; los contratos para la formación-9.637- un incremento del 55,24\% sobre 6.208 de marzo de 2013; y los contratos en prácticas -3.917- un aumento del 54,58\% sobre 2.534 de marzo de 2013.

\subsection{Los contratos formativos}

Existen dos tipos de contratos cuya causa se refiere a la formación y que se hallan regulados en el artículo 11 del Estatuto de los Trabajadores.

El contrato en prácticas, tiene como objeto facilitar la obtención de la práctica profesional adecuada al nivel de estudios o de formación cursados por los trabajadores con título universitario o de formación profesional de grado medio o superior.

El contrato para la formación, tiene por objeto la adquisición de una formación técnica y práctica necesaria para el desempeño adecuado de un puesto de trabajo que requiera un nivel de cualificación.

Hasta 31 de diciembre de 2013 se habían suscrito 106.101 contratos para la formación, en 2012 en las mismas fechas eran 60.584 los contratos firmados de este tipo, lo que supone un incremento en 2013 del 75,13\%. En los cuatro primeros meses de 2014 se han formalizado 41.787 contratos para la formación frente a los 
27.678 del mismo período de 2013, lo que supone un incremento del 50,98\%.

En materia de formación se han incorporado nuevos conceptos como la denominada cuenta de formación, asociada al número de afiliación a la Seguridad Social, en la que se recoja por los Servicios Públicos de Empleo toda la formación profesional acreditable del trabajador; el derecho a un permiso retribuido para formación de 20 horas al año, lo que supone una nueva obligación para las empresas; el Programa de sustitución de trabajadores en formación por trabajadores beneficiarios de prestaciones por desempleo, al que podrán acogerse todas las empresas que sustituyan a sus trabajadores por desempleados beneficiarios de prestaciones por desempleo, durante el tiempo en que aquéllos participen en acciones de formación financiadas por cualquiera de las Administraciones Públicas; la incorporación de los centros y entidades de formación como solicitantes directos de subvenciones para formación de oferta o la participación en el diseño y planificación del subsistema de formación para el empleo de la representación de los centros y entidades de formación.

No cabe duda que la formación puede ser uno de los elementos definidores para poder solventar la situación de desempleo en España. Como herramienta, es una de las más eficaces para luchar contra la dualidad del mercado de trabajo, ya que genera una mayor empleabilidad.

\section{Conclusiones}

La situación del mercado de trabajo reclama más reformas, que contribuyan a flexibilizar el mercado de trabajo, eliminando los efectos perniciosos de la dualidad establecida en España desde hace años y que permita generar mayor contratación y disminuir el desempleo.

Son diversos los elementos pueden ser mejorados y/o ampliados y que se resumen en las siguientes materias.

Se ha de potenciar abiertamente el contrato a tiempo parcial y la consideración del contrato de formación como de inserción, al menos con alcance coyuntural.

También es precisa una mayor atención a la contratación temporal que, especialmente, en la reforma laboral de 2010 sufrió severas limitaciones en el contrato por obra o servicio y eventual. Además no se ha apostado por las posibilidades de las empresas de trabajo temporal en la contratación temporal e indefinida.

En esa línea sería necesario:

1. En el contrato para la formación y el aprendizaje, es necesaria la consideración del contrato de formación como de inserción, al menos con alcance coyuntural -hasta que el porcentaje de desempleo sea inferior al $15 \%$-, de forma que sea más atractivo tanto para las empresas como para los propios trabajadores. 
2. Debiera posibilitarse la incorporación de los jóvenes a las empresas y su formación, de manera que les aporte una primera experiencia práctica con vistas a su inserción definitiva en el mercado de trabajo.

3. Conviene permitir que los trabajadores que, con independencia de su edad, se han visto afectados por procesos de readaptación profesional, en sectores en declive o afectados por la crisis, puedan reorientar por esta vía sus conocimientos teóricos y prácticos en una nueva profesión u oficio.

Especialmente, el régimen jurídico de estas modalidades contractuales vinculadas a aspectos formativos debería ser revisado, simplificándolo, para contemplar los supuestos descritos y facilitar la adquisición de la formación teórica y práctica para el desempeño del oficio, teniendo en cuenta que se debe articular un contrato con una orientación, fundamentalmente, de prestación laboral, cualificando al trabajador, definir que la edad de contratación sea lo suficientemente amplia para que se ajuste tanto a supuestos de readaptación profesional como a la realidad del elevado paro juvenil y las dimensiones del fracaso escolar, debería existir una mayor libertad de resolución, con un salario que parta del SMI y se acomode, gradualmente, a las condiciones del convenio, una protección social plena, sin penalizar en costes al empresario y donde la tutoría se debería realizar por colaboración público-privada, sin coste alguno para la empresa.

Asimismo, es imprescindible permitir la cobertura de uno o más contratos de puesta a disposición, respetando íntegramente por parte de las empresas de trabajo temporal el art. 11.2 del Estatuto de los Trabajadores.

En el contrato a tiempo parcial es necesaria la potenciación por medio de la reducción de la complejidad y rigidez de la actual regulación, lo que se conseguiría otorgándole el mismo tratamiento del contrato a tiempo completo con una jornada inferior.

No obstante en su defecto se debería posibilitar una distribución más flexible del tiempo de trabajo, fomentar el contrato indefinido a tiempo parcial como alternativa a la contratación temporal, ampliar el número de horas complementarias, posibilitando su realización en contratos de duración determinada, permitir ofrecer a los trabajadores el paso de un contrato a tiempo completo a uno a tiempo parcial cuando existan causas económicas, técnicas, organizativas o de producción que puedan justificar el despido, y esta modificación sustancial sea una alternativa a los despidos por tales causas empresariales y finalmente, revisar algunos aspectos técnico-jurídicos que limitan las horas complementarias que figuran en el contrato, tales como los plazos de preaviso o las causas de la denuncia por el trabajador del pacto de horas complementarias.

En la contratación temporal, se deben eliminar las restricciones a la con- 
catenación de contratos y especialmente evitar que opere la suma de contratos concertados con el mismo trabajador para diferente puesto de trabajo, así como en la contratación con el mismo grupo de empresas y en los supuestos de sucesión o subrogación empresarial.

Teniendo en cuenta que el contrato temporal podría ser a tiempo completo o a tiempo parcial, aplicándose las medidas de potenciación que hemos indicado para el contrato indefinido a tiempo parcial.

Efectivamente, la reforma del mercado de trabajo español está ayudando al país a entrar con bien pie en una nueva fase del ciclo económico. Esto se aprecia en la creación de puestos de trabajo, aún con leves crecimientos del PIB, y en la contención de los costes salariales. Ambas mejoras inciden positivamente en los dos principales problemas de la economía y del mercado de trabajo españoles: el paro y los sobrecostes. La reforma laboral estimula el empleo y la competitividad.

Cabe aprovechar la mejora de la actividad y del empleo para culminar la reforma laboral española. Ahora la tarea pendiente es introducir algún nuevo desarrollo legislativo que complete varios destacados flecos de la reforma laboral y que, en particular, mejore su implementación, introduciendo mayor sencillez y claridad en la contratación y mayor seguridad jurídica en la negociación colectiva.

Es necesario, por tanto, un mecanismo claro de simplificación contractual, que no consista en una mera aplicación informática, sino una clara apuesta por un único contrato o dos, con un régimen más flexible, especialmente un coste menor en materia de indemnizaciones.

Una apuesta clara de este tipo supondría el paso principal para la desaparición del fenómeno negativo de la dualidad del mercado de trabajo español, que tantos efectos negativos está teniendo hasta la actualidad. Hay que reorientar las políticas del mercado de trabajo para obtener mejores resultados sociales y en materia de empleo, implicando a todos los actores: empresas, trabajadores, interlocutores sociales y servicios públicos de empleo.

\section{REFERÊNCIAS}

Comisión Europea, Documento de Evaluación de la Estrategia de Lisboa, 2 de febrero de 20 2010. SEC(2010) 114 final.

DOI: 10.1787/empl_outlook-2014-en.

Eurostat.Sharp incrase in unemployment in the EU.Statistics in focus.53/2009.

Eurostat. The impact of the crisis on employment.Statitics in focus.79/2009.

http://ec.europa.eu/europe2020/index_es.htm\#map.

http://ec.europa.eu/europe2020/making-it-happen/annual-growth-surveys/index en.htm. 
http://ec.europa.eu/social/main.jsp?catId=101\&langId=es.

http://ec.europa.eu/social/main.jsp?catId=1047\&langId=en.

http://ec.europa.eu/social/main.jsp?langId=es\&catId=958.

http://epp.eurostat.ec.europa.eu/statistics_explained/index.php/Unemployment_statistics

http://europa.eu/legislation_summaries/glossary/open_method_coordination_ es.htm.

http://europa.eu/pol/pdf/flipbook/es/employment_es.pdf.

http://www.boe.es/boe/dias/2012/02/06/pdfs/BOE-A-2012-1778.pdf.

http://www.eu-employment-observatory.net/.

http://www.mineco.gob.es/stfls/mineco/prensa/noticias/2014/Programa_Reformas_2014.pdf.

http://www.sepe.es/contenidos/que_es_el_sepe/publicaciones/pdf/pdf_empleo/ guia_contratos.pdf

OCDE, Employment Outlook, 2009. Tackling the jobs crisis, págs.61 ss.

OECD (2014), OECD Employment Outlook 2014, OECD Publishing.

OIT, "Proteger a las personas y promover el empleo. Un estudio de las respuestas de los países ante la crisis económica mundial en la esfera de las políticas de empleo y de protección social", septiembre de 2009, págs. 46 y ss. 